An ectomycorrhizal symbiosis differently affects host susceptibility to two congeneric fungal pathogens

Peer-reviewed author version

Gonthier, Paolo; Giordano, Luana; Zampieri, Elisa; Lione, Guglielmo; Vizzini, Alfredo; COLPAERT, Jan \& Balestrini, Raffaella (2019) An ectomycorrhizal

symbiosis differently affects host susceptibility to two congeneric fungal pathogens.

In: FUNGAL ECOLOGY, 39, p. 250-256.

DOI: 10.1016/j.funeco.2018.12.008

Handle: http://hdl.handle.net/1942/28944 


\title{
An ectomycorrhizal symbiosis differently affects host susceptibility to two congeneric fungal pathogens
}

\author{
Paolo Gonthier $^{a^{*}}$, Luana Giordano ${ }^{a, b \dagger}$, Elisa Zampieri ${ }^{a \dagger \S}$, Guglielmo Lione ${ }^{a}$, Alfredo Vizzini ${ }^{c, d}$, \\ Jan V. Colpaert ${ }^{\mathrm{e}}$, Raffaella Balestrini ${ }^{\mathrm{d}}$
}

${ }^{a}$ Department of Agricultural, Forest and Food Sciences (DISAFA), University of Torino, Grugliasco, Italy

${ }^{\mathrm{b}}$ Centre of Competence for the Innovation in the Agro-Environmental Field (AGROINNOVA), University of Torino, Grugliasco, Italy

${ }^{\mathrm{c}}$ Department of Life Sciences and Systems Biology (DBIOS), University of Torino, Torino, Italy

${ }^{\mathrm{d}}$ CNR-Institute for Sustainable Plant Protection (IPSP), Torino, Italy

${ }^{\mathrm{e}}$ Centrum voor MilieuKunde (CMK), Universiteit Hasselt, Diepenbeek, Belgium

${ }^{\dagger}$ These authors equally contributed

${ }^{\S}$ Present address: Council for Agricultural Research and Economics (CREA-CI), Vercelli, Italy

* Corresponding author. Department of Agricultural, Forest and Food Sciences (DISAFA), University of Torino, Grugliasco, Italy

E-mail address: paolo.gonthier@unito.it

Telephone: +390116708697

Fax: +390112368697 


\begin{abstract}
The role of ectomycorrhizal fungi in modulating host susceptibility to fungal pathogens is poorly known. Pinus sylvestris susceptibility to two congeneric fungal pathogens was compared between mycorrhizal and non-mycorrhizal plants. The ectomycorrhizal fungus was Suillus luteus, while the pathogens were Heterobasidion irregulare and H. annosum. H. irregulare is native to North-America and invasive to Europe, whereas S. luteus and H. annosum are native to Eurasia. Non-mycorrhizal plants were equally susceptible to both pathogens. Mycorrhizal plants were significantly less susceptible to $H$. annosum than non-mycorrhizal plants, whereas there were no differences when considering $H$. irregulare. The abundance of ectomycorrhizas was negatively and significantly correlated to the level of host susceptibility only to H. annosum. This study shows that the protective role of ectomycorrhizal fungi may differ when the host is challenged by congeneric fungal pathogens. Results add a further clue to explain and predict the invasiveness of $H$. irregulare in Europe.
\end{abstract}

Keywords: biological invasions, coevolution, fungal interactions, Heterobasidion annosum, Heterobasidion irregulare, microbiome, Pinus sylvestris, Suillus luteus, symbiont 


\section{Introduction}

Invasions by alien organisms are recognized as major factors involved in the loss of biodiversity worldwide (Lövei, 1997; Enserink, 1999). Relevant examples of invasive alien species with devastating effects encompass both pests and pathogens (Loo, 2009; Goodenough, 2010; Pimentel, 2011; Liebhold et al., 2012; Santini et al., 2013).

Invasiveness of alien organisms in naïve ecosystems has been often explained with one of three nonmutually exclusive main hypotheses: the enemy release hypothesis, the high ecological adaptation of alien organisms to naïve ecological niches, and the ability of an alien organism to better utilize resources that are underutilized by native organisms (Shea and Chesson, 2002; Wolfe, 2002; Torchin et al., 2003; Lambrinos, 2004; van der Putten et al., 2007). However, the most common explanation for the invasiveness of alien pests and pathogens hinges on the fact that naïve hosts may be highly susceptible to introduced organisms because they have not co-evolved with them (Lee, 2002; Altizer et al., 2003; Parker and Gilbert, 2004; Desprez-Loustau et al., 2007; Morrison and Hay, 2011; Lombardero et al., 2012). Lack of coevolution may result in the absence of those host defense mechanisms that are normally triggered by a process of recognition between co-evolved hosts and pathogens. In turn, low frequency of defense mechanisms maximizes the reproductive potential of pathogens by making a high percentage of individuals in a naïve population susceptible to the attack, thus leading to maximum transmission rates and severe outbreaks (Gómez-Gómez, 2004; Dong et al., 2015). Identifying the main factors driving the invasion of a plant pathogen, may allow not only to improve our predictions of patterns and rates of invasion, but also to design and implement the most effective control strategies (Gonthier and Garbelotto, 2013).

The choice of an appropriate experimental approach is crucial when trying to disentangle factors driving invasions by pathogens: comparative analyses of disease dynamics in introduced and native ranges have been extensively used for that purpose (van Kelunen et al., 2010). However, it has been 
suggested that an equally valid and complementary approach to understand the biology of invasions may rely on the contrast of the epidemiology between alien invasive pathogens and native related ones, provided they share comparable biological traits (Gonthier and Garbelotto, 2013). This contrast is often based on common garden tests comparing the pathogenicity and/or the sporulation potential of alien and native pathogens on potted host plants or on other substrates in the laboratory or in the greenhouse (Anagnostakis, 1992; Thrall and Jarosz, 1994; Kinloch and Dupper, 2002; Santini et al., 2005; Garbelotto et al., 2010).

A well-researched invasion is that of the North American fungal plant pathogen Heterobasidion irregulare Garbel. \& Otrosina introduced into Italy in 1944 [see Gonthier et al. (2007), and references within]. Since 2015, the organism is recommended for regulation by the European and Mediterranean Plant Protection Organization (EPPO, 2015). The co-occurrence in the invasion area of the native congeneric species $H$. annosum (Fr.) Bref., sharing a similar infection biology and host preference for pines (Pinus spp.) (Garbelotto and Gonthier, 2013), has allowed for comparative experiments aimed at identifying the main factors driving the invasion. Common garden experiments have indicated that pathogenicity levels of $H$. irregulare are comparable to those of $H$. annosum when inoculated in seedlings or cuttings of several pine species, both Eurasian and North American. This result suggested the invasion has not been driven by a disproportionate pathogenicity of the alien fungus on native pine species (Garbelotto et al., 2010). On the other hand, inoculations in pine logs have indicated that $H$. irregulare significantly outcompetes $H$. annosum in its saprotrophic ability while colonizing wood tissues (Giordano et al., 2014) and that the former species is fostered in its reproductive potential when interacting with the latter (Giordano et al., 2018). In the epidemiological cycle of both $H$. irregulare and H. annosum, saprotrophic growth plays a dual key role: first in the establishment of new outbreaks through the colonization of freshly-cut stumps; second, in the production of fruit bodies triggered when a stump or a standing dead tree have been thoroughly colonized by a fungal individual (Garbelotto and Gonthier, 2013). Hence, differences in 
transmission potential linked to saprotrophic ability, and not to pathogenicity, may be driving the invasion of the alien H. irregulare in Italy (Gonthier et al., 2014).

The simple bipartite one-host one-pathogen model is currently been debunked by our understanding of the roles that complex animal and plant microbiomes may have in modulating infection events and processes of response to disease (Berendsen et al., 2012; Coyte et al., 2015; Bonito et al., 2016). In fact, other organisms intimately associated with plants can interfere in a variety of ways with the relationship between the host itself and the pathogen (Lebeis, 2014; Schlaeppi and Bulgarelli, 2015). Among these organisms, mycorrhizal fungi are key players as they are ubiquitous components of the plant microbiome that are highly beneficial to plants by greatly enhancing absorption of nutrients, by increasing resistance to biotic stresses, and by providing protection against soilborne root pathogens (Read and Perez-Moreno, 2003; Martin et al., 2007; Pozo et al., 2009; Smith and Read, 2008; Bonfante and Anca, 2009; Bonfante and Genre, 2010; Jung et al., 2012). Ectomycorrhizal symbiosis involving Basidiomycota or Ascomycota is prevalent in forest tree species growing in habitats encompassing boreal, temperate, Mediterranean and some subtropical forest ecosystems (Brundrett, 2002; Martin, 2007; Smith and Read, 2008). Ectomycorrhizal fungi can protect plants against root pathogens via mechanisms such as forming a physical barrier around (hyphal mantle) and within (Hartig net) the roots that restricts the pathogens access to infection sites and photosynthates, or by synthesis of antibiotics, volatile and non-volatile compounds, and cell wall degrading enzymes (Reviewed by Ghorbanpour et al., 2018).

In this study, we tested whether susceptibility to $H$. irregulare and $H$. annosum in the widespread Eurasian pine species Pinus sylvestris L. might be different depending on the presence of the widespread Eurasian ectomycorrhizal fungus Suillus luteus (L.) Roussel. This information might allow to elucidate if ectomycorrhizal fungi play a role in relation to the invasion of $H$. irregulare in Europe. 


\section{Materials and methods}

The model system includes the alien North American fungal plant pathogen $H$. irregulare invasive in Europe, the native related $H$. annosum, and the ectomycorrhizal fungus $S$. luteus, known to be native to Europe (Nguyen et al., 2016) where it is widely distributed in association with the common host species P. sylvestris (Martin et al., 2016).

The model system is relevant as: i) the two Heterobasidion species stand among the most destructive forest pathogens worldwide and share a similar biology (Garbelotto and Gonthier, 2013); and (ii) they have been diverging in allopatry for 34-41 million years (Linzer et al., 2008; Dalman et al., 2010) and based on genome wide comparative analyses are clearly different species (Sillo et al., 2015a).

S. luteus genotype MUT00005740 (Table 1) was grown on sterilized cellophane sheets in Petri dishes filled with Fries and Munzenberger medium ( $\mathrm{pH} 4.8$ ) (Fries, 1978) stored in a dark room at $25^{\circ} \mathrm{C}$ for 7 days. Mature cones of $P$. sylvestris were collected, just before opening, in January 2014 from different trees in Susa Valley (Italy) (4503'19.64'’N; 651'33.76'’E; $1052 \mathrm{~m}$ a.s.1.). Seeds were extracted from cones after 24 hours of incubation at $25^{\circ} \mathrm{C}$ and then stored at $4^{\circ} \mathrm{C}$. One month before the beginning of the experiment, seeds viability was $100 \%$ according to a germination test in a growth chamber. In February 2015, after wing removal, seeds were washed under running tap water for 10 min, disinfected with $\mathrm{H}_{2} \mathrm{O}_{2}(30 \%$, Sigma Aldrich) for $10 \mathrm{~min}$, washed twice with sterile distilled water for $5 \mathrm{~min}$ and placed in alveolus pots containing sterile sieved, washed and moistened perlite and vermiculite (sterilized at $121^{\circ} \mathrm{C}$ for $\left.20 \mathrm{~min}\right)(1: 1 \mathrm{v} / \mathrm{v})$. Seedlings were grown for two months in a growth chamber set at a temperature of $25 \pm 2^{\circ} \mathrm{C}$, a photoperiod of $12 \mathrm{~h}^{\text {day }}{ }^{-1}$ with Photosynthetic Active Radiation (PAR) of $1200 \mu \mathrm{mol} \mathrm{m}^{-2} \mathrm{~s}^{-1}$, and watered once a week with distilled water. Half of them was inoculated with $S$. luteus by using the sandwich technique described by 
Colpaert et al. (1999). Subsequently, all pine seedlings were transferred in 8x8x8 cm pots, containing sterile perlite/vermiculite $(1: 1 \mathrm{v} / \mathrm{v})$, and kept in a growth chamber in the same conditions described above. Seedlings were watered once a week with tap water. The presence of $S$. luteus was checked 50 days after inoculations by verifying the presence of mycorrhizal primordia under a dissecting microscope as described by Agerer (1987-1993). Seedlings displaying mycorrhizal primordia were deemed mycorrhizal at that time, and are hereafter referred to as "mycorrhizal 50d".

Three heterokaryotic (ploidy: $\mathrm{n}+\mathrm{n}$ ) genotypes of $H$. irregulare and three of H. annosum (Table 1) preselected based on their high pathogenicity on $P$. sylvestris seedlings from a sample of 8 genotypes per species (not shown) were used in this study. All six genotypes were deposited at the Mycotheca Universitatis Taurinensis (MUT) with the accession numbers listed in Table 1. It should be noted that although collected in Italy all $H$. irregulare genotypes used in this study were screened for the absence of introgressed H. annosum alleles (Gonthier and Garbelotto, 2011) and that pure $H$. irregulare populations in Italy are genetically and phenotypically indistinguishable from North American ones (Linzer et al., 2008; Garbelotto et al., 2010; Garbelotto et al., 2013). The genotypes were stored at $4^{\circ} \mathrm{C}$ and ten days before pathogen inoculations they were sub-cultured in Petri dishes filled with MEA (Malt Extract Agar: $31.3 \mathrm{~g}$ malt extract agar, $1 \mathrm{~L}$ distilled water). Pathogen inoculations were conducted on seven months old $P$. sylvestris seedlings both mycorrhizal 50d and non-mycorrhizal. Inoculations were carried out with each pathogen genotype by placing at the base of seedling stems two $5 \mathrm{~mm}$ diameter mycelial plugs excised from the edge of actively growing colonies, after having produced a little wound by using a sterile scalpel. Subsequently, plugs were gently covered with sterile perlite/vermiculite in order to avoid dryness. Controls included mycorrhizal 50d and non-mycorrhizal seedlings treated as described above but with sterile agar plugs. Seedlings were distributed according to a complete randomized design in the growth chamber set with the parameters described above and were inspected every day for appearance of disease symptoms such as needle discoloration and crown wilting. Seedling death was assumed to have 
occurred when needles became tough or crown collapsed. The time to death of each seedling, expressed as the number of days after pathogen inoculation, was recorded.

The experiment was stopped when at least $90 \%$ of seedlings inoculated with the pathogens died. At the end of the experiment, isolations were carried out from stems of all inoculated seedlings to confirm the presence of the pathogens according to the methods previously described (Garbelotto et al., 2010). At the end of the experiment, the presence of fully developed ectomycorrhizas was checked under a dissecting microscope as described by Agerer (1987-1993). Seedlings displaying fully developed morphotypes of $S$. luteus at that time were considered mycorrhizal, and are hereafter referred to as "mycorrhizal at the end of experiment (EoE)". The total number of S. luteus ectomycorrhizas was determined in mycorrhizal EoE seedlings as previously described (Zampieri et al., 2017). The root systems were excised at the collar from the remaining portions of seedlings by using a sterile scalpel, and weighted with a precision balance $( \pm 0.0001 \mathrm{~g})$. For each seedling, the mycorrhizal density was calculated as the ratio between the total number of ectomycorrhizas and the weight of the root system.

To assess the level of host susceptibility, the time necessary for the pathogen to kill the seedlings, i.e. time to death (days), was used. Time to death and level of host susceptibility were assumed to be negatively correlated. The time to death was averaged for each treatment (mycorrhizal 50d or mycorrhizal EoE and non-mycorrhizal seedlings) within fungal pathogenic species (H. irregulare and H. annosum) and the $95 \%$ bootstrap bias-corrected and accelerated confidence intervals (CI) of the averages were calculated based on 10000 iterations per interval (DiCiccio and Efron, 1996). The survival analysis was performed by fitting for both pathogenic species the Kaplan-Meier curves associated with treatments (Kaplan and Meier, 1958; Crawley, 2013). The log-rank test was carried out to compare the survival curves between non-mycorrhizal seedlings and mycorrhizal 50d or mycorrhizal EoE (Harrington and Fleming, 1982) as well as between non-mycorrhizal seedlings inoculated with $H$. irregulare and H. annosum. A correlation analysis based on the Spearman's $\rho$ 
coefficient was carried out between the time to death and the mycorrhizal density of seedlings inoculated with Heterobasidion spp. The same analysis was performed on the two subsets of seedlings inoculated with either $H$. irregulare, or H. annosum. $P$-values associated with the S statistics were calculated under the exact, AS 89 and t distributions (Best and Roberts, 1975; van de Wiel and Di Bucchianico, 2001; Crawley, 2013). The survival and the correlation analyses were run in R 3.2.1 with the library "survival" and "pspearman”, respectively (R Core Team, 2014; Savicky, 2014; Therneau, 2014). The significance threshold was set at 0.05 for all statistical analyses. Data are provided as Supplementary Material S1.

\section{Results}

All control seedlings, regardless of their mycorrhization status, were still living and symptomless one month after the end of the experiment. Conversely, $95 \%$ of seedlings inoculated with $H$. irregulare and $93 \%$ of seedlings inoculated with $H$. annosum died within 26 days from the time of inoculation. Seedling death was not preceded by needle discoloration or by other symptoms. Rather, it occurred suddenly in the form of crown collapse similar to a damping off in the $80 \%$ of seedlings and of needle toughing in the remaining $20 \%$ of seedlings. Presence of each pathogen was confirmed by its re-isolation on culture media. All of the seedlings inoculated with S. luteus were mycorrhizal (i.e. displayed mycorrhizal primordia) 50 days after inoculations. Mycorrhizal primordia were young ectomycorrhizas up to $1 \mathrm{~mm}$ long, whitish to light cream, with scarce emanating elements (hyphae and rhizomorphs) and a still incompletely formed mantle. Forty-five percent of seedlings inoculated with $S$. luteus were mycorrhizal (i.e. showed fully developed mycorrhizas) at the end of the experiment based on descriptions reported in Agerer (1987-1993). 
The average time to death caused by $H$. irregulare was 18.8 days (15.2-21.8 95\% CI) for the 21 mycorrhizal 50d seedlings, 18.2 days $(13.7-21.995 \% \mathrm{CI})$ for the 10 mycorrhizal EoE seedlings, and 15.2 days (12.4-18.1 95\% CI) for the 21 non-mycorrhizal ones. Contrasts between survival curves (Fig. 1A) did not show significant differences when comparing mycorrhizal 50d and nonmycorrhizal-seedlings or mycorrhizal EoE and non-mycorrhizal seedlings (Table 2).

The average time to death caused by H. annosum was 22.9 days (20.5-24.4 95\% CI) for the 21 mycorrhizal 50d seedlings, 24.4 days $(22.4-25.6$ 95\% CI) for the 9 mycorrhizal EoE seedlings, and 17.3 days (14.7-20.0 95\% CI) for the 21 non-mycorrhizal ones. Survival curves (Fig. 1B) of mycorrhizal 50d and mycorrhizal EoE seedlings were both significantly different than the survival curve of non-mycorrhizal seedlings (Table 2). Finally, no significant differences emerged from the comparison between survival curves of non-mycorrhizal seedlings inoculated with the two pathogenic fungal species (Table 2).

The time to death and the mycorrhizal density of all seedlings inoculated with Heterobasidion spp. were positively and significantly correlated (Table 3 ). Correlation was even stronger when the analysis was conducted on the subset of seedlings challenged with H. annosum (Table 3).

Conversely, a non-significant Spearman's coefficient resulted from the correlation analysis carried out on seedlings inoculated with $H$. irregulare (Table 3 ). The $P$-values were consistent in accepting or rejecting the null hypothesis (i.e. $\rho=0$ ), regardless of the distribution of the $\mathrm{S}$ statistics (Table 3).

\section{Discussion}

By using a simple experimental design, we were able to detect a differential response when a plant species associated with an ectomycorrhizal fungus was challenged by two congeneric fungal plant pathogens. This finding was particularly remarkable in light of the fact the two pathogens, although 
evolved in allopatry, are closely related species reaching $98 \%$ of genomic similarity (Sillo et al., 2015) and are characterized by similar biology and host preference (Garbelotto and Gonthier, 2013). It should be noted that both $H$. irregulare and $H$. annosum are necrotrophic fungal pathogens that may gain access into the tree through wounds, and may subsequently attack the cambium layer (Garbelotto and Gonthier, 2013). Therefore, the inoculation methods we used seems suitable to mimic what occurs in nature. Hence, it is not surprising that potted host seedlings in the laboratory or in the glasshouse are generally inoculated at the stem level through wounds to study the pathogenicity of Heterobasidion spp. (Garbelotto et al., 2007, 2010; Pollastrini et al., 2015; Zampieri et al., 2017; Pepori et al., 2018). Conversely from what reported elsewhere in the literature, most of the plant mortality in our experiment occurred as a result of sudden crown collapse similar to damping off. Such rapid collapse on one hand is likely related to the limited size of seedling stems (diameter less than $1.5 \mathrm{~mm}$ ), on the other hand it minimized the error margin potentially associated with the scoring of time to death.

Despite the role of mycorrhizal symbiosis in the protection of plants from infectious fungal diseases is not new (Pozo et al., 2009; Smith and Read, 2008), it is worth noting that most information is available for arbuscular endomycorrhizal fungi, rather than for ectomycorrhizal ones (Ramchela and Theron, 2010). Furthermore, in our study the ectomycorrhizas-mediated protection was tested using an invasive fungal pathogen and a closely related native one in the attempt to elucidate if ectomycorrhizal fungi may play a role in relation to the ongoing invasion of $H$. irregulare in Europe. Results indicated that, in the absence of the root-associated symbiotic fungus, the host was equally susceptible to both pathogen species, which is consistent with previously published data (Garbelotto et al., 2010; Pollastrini et al., 2015; Pepori et al., 2018). Conversely, while the presence of the symbiont significantly reduced the susceptibility of the host challenged with $H$. annosum, there was no effect on susceptibility when the host was challenged with the invasive $H$. irregulare. The differential effects of S. luteus ectomycorrhizas on the level of susceptibility of the host plant to $H$. 
annosum and H. irregulare were also showed by the correlation analyses between the lifetime of seedlings and the mycorrhizal density. While a correlation between these two variables might be expected as a consequence of the protective role exerted by the mutualist symbiosis on the host plant (Filion et al., 1999; Pozo and Azcón-Aguilar, 2007), in our experiment, rather surprisingly, a significant correlation was detected only for seedlings infected with $H$. annosum, but not for seedlings infected with $H$. irregulare. Apparently, the presence and the increasing abundance of ectomycorrhizas might successfully thwart $H$. annosum, while failing against $H$. irregulare. Data suggest that $P$. sylvestris plants mycorrhized with $S$. luteus may be more susceptible to $H$. irregulare than to $H$. annosum. Although the differences of susceptibility levels observed in our experiment between mycorrhizal and non-mycorrhizal $P$. sylvestris seedlings were statistically supported, their magnitude might be deemed limited. Nonetheless, the above differences were independently confirmed by two different statistical approaches, the first one (i.e. Kaplan-Meier curves) analyzing the survivorship of infected seedlings based on presence/absence of ectomycorrhizal symbiosis, and the second one (i.e. Spearman's correlation) appraising quantitatively the positive effect possibly exerted by the symbiosis. It is worth noting that for Heterobasidion spp. a substantial agreement between the outcomes of inoculation trials and in-field impact of the pathogens has been previously reported (Swedjemark and Stenlid, 1995). Moreover, both the sampling size and the experimental design we used are comparable with previously published trials assessing mortality rates of pine seedlings with similar stem size and inoculated with Heterobasidion spp. (Olson and Stenlid, 2001). The evidence gathered from our study suggests that should $H$. irregulare spread to $P$. sylvestris forests it may lead to damages comparatively more relevant than those currently caused by H. annosum in the same stands. It also seems plausible that the mechanism here described may apply particularly in those cases where Heterobasidion spp. affect pine regeneration: in fact, infection by these wood decay pathogens may be more strongly influenced by mycorrhizal-induced physiological 
changes in juveniles, and less influenced by the ecology of wood, as it is reported to happen when Heterobasidion individuals infect larger trees or stumps.

The competitive advantage demonstrated for $H$. irregulare may be the result not only of its higher transmission rate compared to that of H. annosum (Gonthier et al., 2014), but may also be due to the fact that ectomycorrhizal associations do not seem to exert any significant protective role against $H$. irregulare. Although S. luteus is largely widespread on P. sylvestris in Europe (Muñoz, 2005), it is well known that trees are associated with multiple mycorrhizal symbionts (Mohatt et al., 2008): whether trees with multiple mycorrhizal associations will perform in the same way remains an open question.

Although the mechanisms underlying the differential susceptibility of mycorrhizal plants to $H$. irregulare and $H$. annosum are largely unknown, all lines of evidence suggest that a direct interaction between symbiont and pathogen is unlikely. In fact, morphological and gene expression studies based on experiments in vitro using the same fungal genotypes but excluding the host have failed to detect any differential interaction between the mycorrhizal fungus and either one of the pathogens (Sillo et al., 2015b). Another recent study, again conducted using the same pathogen genotypes employed here, but focusing on Pinus pinea L. as a host and Tuber borchii Vittad. as a symbiont, suggested that a recognition mechanism through host plant-mediated signal transduction was involved between a $T$. borchii and H. annosum, but not between T. borchii and H. irregulare (Zampieri et al. 2017), supporting an indirect rather than a direct interaction between host symbiont and pathogen. This hypothesis could provide a clue to interpret the lack of correlation between the host susceptibility to H. irregulare and the abundance of ectomycorrhizas.

It is worth noting that our results were consistent regardless of the moment in which the mycorrhization was assessed (i.e. 50 days after the inoculation of the ectomycorrhizal fungus or at the end of the experiment), suggesting that the host reaction to infection might involve cross-talk and self-recognition between the mycorrhizal fungus and $H$. annosum even at the earliest stage of 
symbiotic interaction. Although these findings are intriguing, the mechanisms underlying this tripartite interaction still ought to be elucidated.

Even though in this study we investigated a complex tripartite interaction, which is an improvement compared to the one-host one-pathogen approach normally applied by plant pathologists, we are aware that even the tripartite interaction might be simplistic in the light of the latest findings on the plant microbiome and on the complexity of ecological and biological interrelations networking bionts at different time and spatial scales (Jordano et al., 2003; Berendsen et al., 2012; Lebeis, 2014; Coyte et al., 2015; Schlaeppi and Bulgarelli, 2015; Dickie et al., 2017). Regardless of the long-lasting epistemic debate contrasting reductionism and holism in scientific research, functional insights are still largely derived from experiments using individual microorganisms (Schlaeppi and Bulgarelli, 2015) and unrevealing simple interactions within subsystems may provide solid clues to interpret more complex patterns (Odum and Barrett, 1971; Albert and Barabási, 2002).

The differential response observed in host plants inoculated with $H$. irregulare and $H$. annosum could be either ascribed to a species effect and/or to a genotype effect. Although genotype effects cannot be completely ruled out, it should be noted that species effects rather than genotype effects were detected when testing the competitive ability of the two species (Giordano et al., 2014). Since $H$. irregulare and H. annosum evolved in allopatry, we cannot exclude as well that the observed differential response in host plants could be related to the lack of coevolution between $H$. irregulare, $P$. sylvestris and $S$. luteus, both the latter native to Europe, although $S$. luteus has been introduced to North America with P. sylvestris (Nguyen et al., 2016), thus not earlier than in the $19^{\text {th }}$ century (McMurry, 1999). Thus, while the differential response in host plants inoculated with $H$. irregulare and $H$. annosum can be ascribed to a species effect of the pathogen, our experimental design does not allow to draw conclusions about the role of the geographic origin of the pathogen, and hence of the lack of coevolution between alien and native organisms in this model system. To determine whether the geographic origin of the pathogen may play a role in this and other model systems, further 
experiments should be conducted by using additional alien and native symbiont, plant and pathogen species and genotypes, including Pinus and Suillus species/genotypes from North America. In conclusion, this work provides a new piece of information about the potential invasiveness and impact of an important fungal forest pathogen alien to Europe, shedding a new light on the different role played by an ectomycorrhizal fungus in the protection of its host against an invasive or a native congeneric pathogen. While no general conclusions may be drawn on the effects of the lack of coevolution between pathogens and host symbionts, our pioneering experiment suggests that this field of research should be further and fully explored. Outcomes from this field of research could be of pivotal importance not only for plant pathologists, but also for conservation biologists and policymakers, since new pathogen-host-symbiont combinations are likely to be on the rise. In fact, not only introductions of alien plant pathogens are increasing, but also the less known yet documented introductions of exotic ectomycorrhizal fungi will be predictably more and more frequent (Vellinga et al., 2009; Nguyen et al., 2016; Dickie et al., 2017).

\section{Acknowledgments}

This work was supported by the Italian Ministry of Education, University and Research, within the FIRB program (grant number RBFR1280NN). Authors are grateful to François Rineau for assistance with mycorrhiza inoculations and to Matteo Garbelotto for helpful comments on the manuscript and for revising the English. The authors wish to thank the Editor and the anonymous Reviewers for insightful suggestions on how to improve the manuscript.

\section{References}


Agerer, R., 1987-1993. Colour Atlas of Ectomycorrhizae. Schwabisch Gmund, Einhorn-Verlag. Albert, R., Barabási, A.L., 2002. Statistical mechanics of complex networks. Rev. Mod. Phys. 74, 47-97.

Altizer, S., Harvell, D., Friedle, E., 2003. Rapid evolutionary dynamics and disease threats to biodiversity. Trends Ecol. Evol. 18, 549-604.

Anagnostakis, S.L., 1992. Measuring resistance of chestnut trees to chestnut blight. Can. J. For. Res. $22,568-571$.

Berendsen, R.L., Pieterse, C.M., Bakker, P.A., 2012. The rhizosphere microbiome and plant health. Trends Plant Sci. 17, 478-486.

Brundrett, M.C., 2002. Coevolution of roots and mycorrhizas of land plants. New Phytol. 154, 275304.

Bonfante, P., Anca, I.A., 2009. Plants, mycorrhizal fungi, and bacteria: a network of interactions. Annu. Rev. Microbiol. 63, 363-383.

Bonfante, P., Genre, A., 2010. Mechanisms underlying beneficial plant-fungus interactions in mycorrhizal symbiosis. Nat. Commun. 1, 48.

Best, D.J., Roberts, D.E., 1975. Algorithm AS 89: the upper tail probabilities of Spearman's rho. Appl. Stat. 24, 377-379.

Bonito, G., Hameed, K., Ventura, R., Krishnan, J., Schadt, C.W., Vilgalys, R., 2016. Isolating a functionally relevant guild of fungi from the root microbiome of Populus. Fungal Ecol. 22, 35-42. Colpaert, J.V., Van Tichelen, K.K., Van Assche, J.A., Van Laere, A., 1999. Short term phosphorus uptake rates in mycorrhizal and non-mycorrhizal roots of intact Pinus sylvestris seedlings. New Phytol. 143, 589-597.

Coyte, K.Z., Schluter, J., Foster, K.R., 2015. The ecology of the microbiome: networks, competition, and stability. Science 350, 663-666.

Crawley, M.J., 2013. The R Book, second ed. Wiley, Chichester. 
Dalman, K., Olson, Å., Stenlid, J., 2010. Evolutionary history of the conifer root rot fungus Heterobasidion annosum sensu lato. Mol. Ecol. 19, 4979-4993.

Desprez-Loustau, M.L., Robin, C., Buée, M., Courtecuisse, R., Garbaye, J., Suffert, F., et al., 2007. The fungal dimension of biological invasions. Trends Ecol. Evol. 22, 472-480.

DiCiccio, T.J., Efron, B., 1996. Bootstrap confidence intervals. Stat. Science 11, 189-228.

Dickie, I.A., Bufford, J.L., Cobb, R.C., Desprez-Loustau, M.L., Grelet, G., Hulme, P.E., et al., 2017. The emerging science of linked plant-fungal invasions. New Phytol. 215, 1314-1332.

Dong, S., Raffaele, S., Kamoun, S., 2015. The two-speed genomes of filamentous pathogens: waltz with plants. Curr. Opin. Genet Dev. 35, 57-65.

Enserink, M., 1999. Biological invaders sweep in. Science 285, 1834-1836.

EPPO, 2015. Pest risk analysis for Heterobasidion irregulare. EPPO, Paris. http://www.eppo.int/QUARANTINE/Pest_Risk_Analysis/PRA_intro.htm accessed: 18.03.2018 Filion, M., St-Arnaud, M., Fortin, J.A., 1999. Direct interaction between the arbuscular mycorrhizal fungus Glomus intraradices and different rhizosphere microorganisms. New Phytol. 141, 525-533. Fries, N., 1978. Basidiospore germination in some mycorrhiza-forming Hymenomycetes. Mycol. Res. 70, 319-324.

Garbelotto, M., Gonthier, P., 2013. Biology, epidemiology, and control of Heterobasidion species worldwide. Annu. Rev. Phytopathol. 51, 39-59.

Garbelotto, M., Guglielmo, F., Mascheretti, S., Croucher, P.J.P., Gonthier, P., 2013. Population genetic analyses provide insights on the introduction pathway and spread patterns of the North American forest pathogen Heterobasidion irregulare in Italy. Mol. Ecol. 22, 4855-4869.

Garbelotto, M., Linzer, R., Nicolotti, G., Gonthier, P., 2010. Comparing the influences of ecological and evolutionary factors on the successful invasion of a fungal forest pathogen. Biol. Invasions 12 , 943-957. 
Ghorbanpour, M., Omidvari, M., Abbaszadeh-Dahaji, P., Omidvar, R., Kariman, K., 2018.

Mechanisms underlying the protective effects of beneficial fungi against plant diseases. Biol. Control $117,147-157$.

Giordano, L., Gonthier, P., Lione, G., Capretti, P., Garbelotto, M., 2014. The saprobic and fruiting abilities of the exotic forest pathogen Heterobasidion irregulare may explain its invasiveness. Biol. Invasions $16,803-814$.

Giordano, L., Gonthier, P., Lione, G., Garbelotto, M., 2018. The invasiveness of a non-native fungal forest pathogen is boosted by the presence of a congeneric native species. Forestry, in press. Doi: 10.1093/forestry/cpy042.

Gómez-Gómez, L., 2004. Plant perception systems for pathogen recognition and defence. Mol. Immunol. 41, 1055-1062.

Gonthier, P., Anselmi, N., Capretti, P., Bussotti, F., Feducci, M., Giordano, L., et al., 2014. An integrated approach to control the introduced forest pathogen Heterobasidion irregulare in Europe. Forestry $87,471-481$.

Gonthier, P., Garbelotto, M., 2011. Amplified fragment length polymorphism and sequence analyses reveal massive gene introgression from the European fungal pathogen Heterobasidion annosum into its introduced congener H. irregulare. Mol. Ecol. 20, 2756-2770.

Gonthier, P., Garbelotto, M., 2013. Reducing the threat of emerging infectious diseases of forest trees. CAB Rev. 8, 1-2.

Gonthier, P., Nicolotti, G., Linzer, R., Guglielmo, F., Garbelotto, M., 2007. Invasion of European pine stands by a North American forest pathogen and its hybridization with a native interfertile taxon. Mol. Ecol. 16, 1389-400.

Goodenough, A., 2010. Are the ecological impacts of alien species misrepresented? A review of the "native good, alien bad" philosophy. Community Ecol. 11, 13-21. 
Harrington, D.P., Fleming, T.R., 1982. A class of rank test procedures for censored survival data. Biometrika 69, 553-566.

Jordano, P., Bascompte, J., Olesen, J.M., 2003. Invariant properties in coevolutionary networks of plant-animal interactions. Ecol. Lett. 6, 69-81.

Jung, S.C., Martinez-Medina, A., Lopez-Raez, J.A., Pozo, M.J., 2012. Mycorrhiza-induced resistance and priming of plant defenses. J. Chem. Ecol. 38, 651-664.

Kaplan, E.L., Meier, P., 1958. Nonparametric estimation from incomplete observations. J. Am. Stat. Assoc. 53, 457-481.

Kinloch Jr., B.B., Dupper, G.E., 2002. Genetic specificity in the white pine-blister rust pathosystem. Phytopathology 92, 278-280.

Lambrinos, J.G., 2004. How interactions between ecology and evolution influence contemporary invasion dynamics. Ecology 85, 2061-2070.

Lebeis, S.L., 2014. The potential for give and take in plant-microbiome relationships. Front Plant Sci. 5, 287.

Lee, C.E., 2002. Evolutionary genetics of invasive species. Trends Ecol. Evol. 17, 386-391.

Liebhold, A.M., Brockerhoff, E.G., Garrett, L.J., Parke, J.L., Britton, K.O., 2012. Live plant imports: the major pathway for forest insect and pathogen invasions of the US. Front. Ecol. Environ. 10, 135143.

Linzer, R.E., Otrosina, W.J., Gonthier, P., Bruhn, J., Laflamme, G., Bussieres, G., et al., 2008. Inferences on the phylogeography of the fungal pathogen Heterobasidion annosum, including evidence of interspecific horizontall genetic transfer and of human-mediated, long-range dispersal. Mol. Phylogenet. Evol. 46, 844-862.

Lombardero, M.J., Alonso-Rodríguez, M., Roca-Posada, E.P., 2012. Tree insects and pathogens display opposite tendencies to attack native vs. non-native pines. For. Ecol. Manage. 281, 121-129. 
Loo, J.A., 2009. Ecological impacts of non-indigenous invasive fungi as forest pathogens. Biol. Invasions 11, 81-96.

Lövei, G.L., 1997. Biodiversity: Global change through invasion. Nature 388, 627-628.

Martin, F., 2007. Fair trade in the underworld: the ectomycorrhizal symbiosis. In: Howard, R.J., Gow, N.A.R. (Eds.), The Mycota VIII. Biology of the Fungal Cell. Springer-Verlag, Berlin, pp. 289306.

Martin, F., Kohler, A., Duplessis, S., 2007. Living in harmony in the wood underground: ectomycorrhizal genomics. Curr. Opin. Plant Biol. 10, 204-210.

Martin, F., Kohler, A., Murat, C., Veneault-Fourrey, C., Hibbett, D.S., 2016. Unearthing the roots of ectomycorrhizal symbioses. Nat. Rev. Microbiol. 14, 760-773.

McMurry, S., 1999. Evolution of a landscape: from farm to forest in the Adirondack Region, 18571894. N. Y. Hist. 80, 117-152.

Mohatt, K.R., Cripps, C.L., Lavina, M., 2008. Ectomycorrhizal fungi of whitebark pine (a tree in peril) revealed by sporocarps and molecular analysis of mycorrhizae from treeline forests in the Greater Yellowstone Ecosystem. Botany 86, 14-25.

Morrison, W.E., Hay, M.E., 2011. Herbivore preference for native vs. exotic plants: generalist herbivores from multiple continents prefer exotic plants that are evolutionarily naïve. PLoS One 6, e17227.

Muñoz, J.A., 2005. Boletus s.l. (excl. Xerocomus). Fungi Europaei 2. Edizioni Candusso, Alassio. Nguyen, N.H., Vellinga, E.C., Bruns, T.D., Kennedy, P.D., 2016. Phylogenetic assessment of global Suillus ITS sequences supports morphologically defined species and reveals synonymous and undescribed taxa. Mycologia 108, 1216-1228.

Odum, E.P., Barrett, G.W., 1971. Fundamentals of Ecology (Vol. 3). Saunders, Philadelphia. Olson, Å., Stenlid, J., 2001. Mitochondrial control of fungal hybrid virulence. Nature 411, 438. 
Parker, I.M., Gilbert, G.S., 2004. The evolutionary ecology of novel plant-pathogen interactions. Annu. Rev. Ecol. Evol. Syst. 35, 675-700.

Pepori, A.L., Michelozzi, M., Santini, A., Cencetti, G., Bonello, P., Gonthier, P., Sebastiani, F., Luchi, N., 2018. Comparative transcriptional and metabolic responses of Pinus pinea to a native and a non-native Heterobasidion species. Tree Physiol., in press. Doi: 10.1093/treephys/tpy086.

Pimentel, D., 2011. Biological Invasions: Economic and Environmental Costs of Alien Plant, Animal, and Microbe Species. CRC Press Inc., Boca Raton.

Pollastrini, M., Luchi, N., Michelozzi, M., Gerosa, G., Marzuoli, R., Bussotti, F., et al., 2015. Early physiological responses of Pinus pinea L. seedlings infected by Heterobasidion sp.pl. in an ozoneenriched atmospheric environment. Tree Physiol. 35, 331-340.

Pozo, M.J., Azcón-Aguilar, C., 2007. Unravelling mycorrhiza-induced resistance. Curr. Opin. Plant Biol. 10, 393-398.

Pozo, M.J., Verhage, A., García-Andrade, J., García, J.M., Azcón-Aguilar, C., 2009. Priming plant defence against pathogens by arbuscular mycorrhizal fungi. In: Azcón-Aguilar, C., Barea, J.M., Gianinazzi, S., Gianinazzi-Pearson, V. (Eds.), Mycorrhizas-Functional Processes and Ecological Impact. Springer Berlin, Heidelberg, pp. 123-135.

R Core Team, 2014. R: A Language and Environment for Statistical Computing. R Foundation for Statistical Computing, Vienna, Austria. URL http://www.R-project.org/

Ramachela, K., Theron, J.M., 2010. Effect of ectomycorrhizal fungi in the protection of Uapaca kirkiana seedlings against root pathogens in Zimbabwe. South. For. 72, 37-45.

Read, D.J., Perez-Moreno, J., 2003. Mycorrhizas and nutrient cycling in ecosystems - a journey towards relevance? New Phytol. 157, 475-492.

Santini, A., Montaghi, A., Vendramin, G.G., Capretti, P., 2005. Analysis of the Italian Dutch elm disease fungal population. J. Phytopathol. 153, 73-79. 
Santini, A., Ghelardini, L., De Pace, C., Desprez-Loustau, M.L., Capretti, P., Chandelier, A., et al., 2013. Biogeographical patterns and determinants of invasion by forest pathogens in Europe. New Phytol. 197, 238-250.

Savicky, P., 2014. pspearman: Spearman's Rank Correlation Test. R Package Version 0.3-0. URL https:/CRAN.R-project.org/package=pspearman

Schlaeppi, K., Bulgarelli, D., 2015. The plant microbiome at work. Mol. Plant Microbe Interact. 28, $212-217$.

Shea, K., Chesson, P., 2002. Community ecology theory as a framework for biological invasions. Trends Ecol. Evolut. 17, 170-176.

Sillo, F., Garbelotto, M., Friedman, M., Gonthier, P., 2015a. Comparative genomics of sibling fungal pathogenic taxa identifies adaptive evolution without divergence in pathogenicity genes or genomic structure. Genome Biol. Evol. 7, 3190-3206.

Sillo, F., Zampieri, E., Giordano, L., Lione, G., Colpaert, J.V., Balestrini, R., et al., 2015b.

Identification of genes differentially expressed during the interaction between the plant symbiont Suillus luteus and two plant pathogenic allopatric Heterobasidion species. Mycol. Progr. 14, 106.

Smith, S.E., Read, D.J., 2008. Mycorrhizal Symbiosis. Academic Press, Cambridge.

Swedjemark, G., Stenlid, J., 1995. Susceptibility of conifer and broadleaf seedlings to Swedish S and P strains of Heterobasidion annosum. Plant Pathol. 44, 73-79.

Therneau, T., 2014. A Package for Survival Analysis in S. R Package Version 2.37-7, URL http://CRAN.R-project.org/package=survival

Thrall, P.H., Jarosz, A.M., 1994. Host-pathogen dynamics in experimental populations of Silene alba and Ustilago violacea. I. Ecological and genetic determinants of disease spread. J. Ecol. 82, 549-559. Torchin, M.E., Lafferty, K.D., Dobson, A.P., McKenzie, V.J., Kuris, A.M., 2003. Introduced species and their missing parasites. Nature 421, 628-630. 
van de Wiel, M.A., Di Bucchianico, A., 2001. Fast computation of the exact null distribution of Spearman's rho and Page's L statistic for samples with and without ties. J. Stat. Plann. Inf. 92, 133145.

van der Putten, W.H., Kowalchuk, G.A., Brinkman, E.P., Doodeman, G.T.A., van der Kaaij, R.M., Kamp, A.F.D., et al., 2007. Soil feedback of exotic savanna grass relates to pathogen absence and mycorrhizal selectivity. Ecology 88, 978-988.

van Kleunen, M., Dawson, W., Schlaepfer, D.R., Jeschke, J.M., Fischer, M., 2010. Are invaders different? A conceptual framework of comparative approaches for assessing determinants of invasiveness. Ecol. Lett. 13, 947-958.

Vellinga, E.C., Wolfe, B.E, Pringle, A., 2009. Global patterns of ectomycorrhizal introductions. New Phytol. 181, 960-973.

Wolfe, L.M., 2002. Why alien invaders succeed: support for the escape-from-enemy hypothesis. The Am. Nat. 60, 705-711.

Zampieri, E., Giordano, L., Lione, G., Vizzini, A., Sillo, F., Balestrini, R., et al., 2017. A nonnative and a native fungal plant pathogen similarly stimulate ectomycorrhizal development but are perceived differently by a fungal symbiont. New Phytol. 213, 1836-1849. 


\section{H. irregulare}

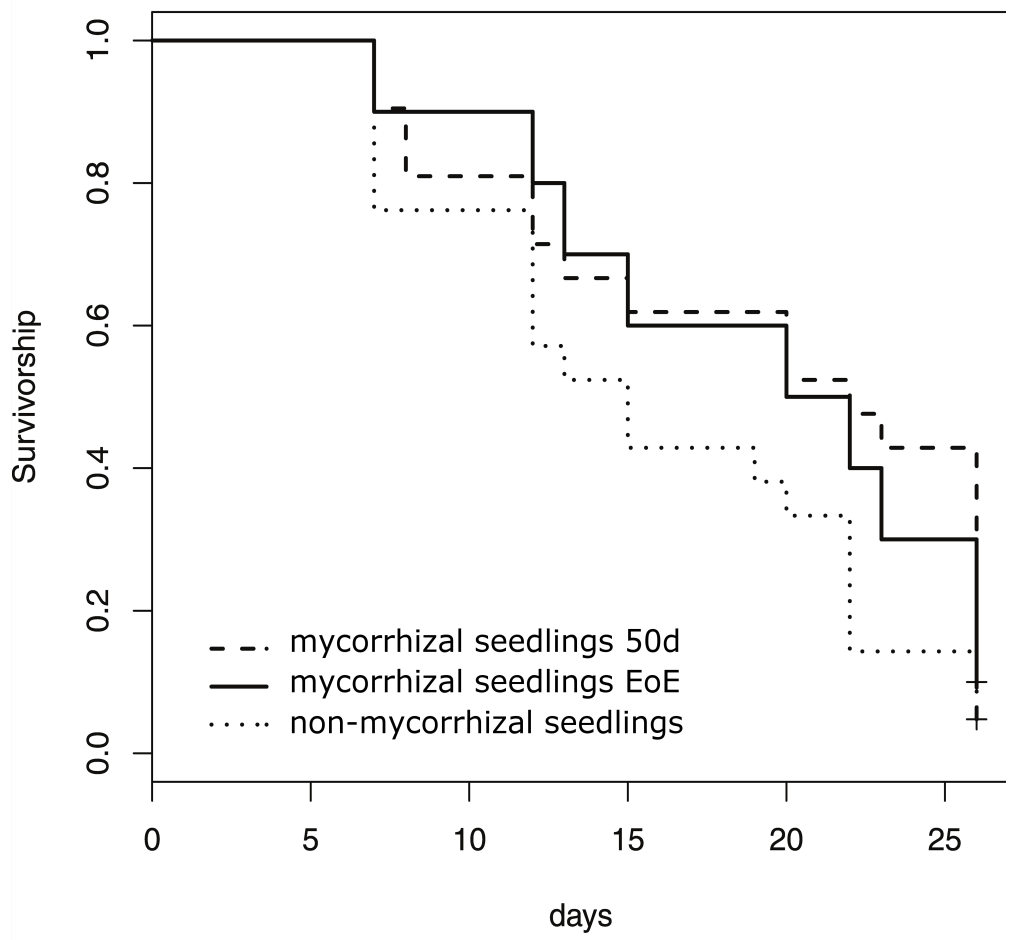

H. annosum

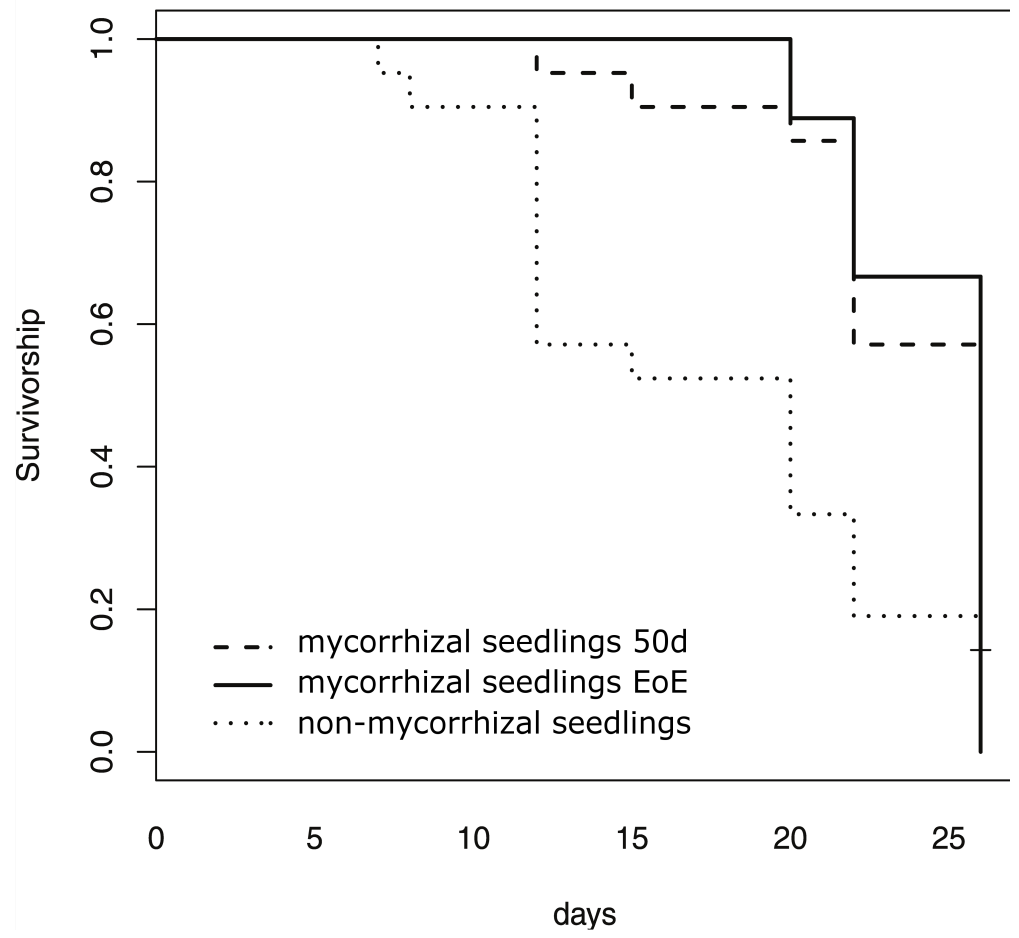

\section{Figure legends}

Fig. 1. Kaplan-Meier survival curves of Pinus sylvestris seedlings inoculated with Heterobasidion irregulare (A) and

H. annosum (B). The curves show the survival of seedlings displaying mycorrhizal primordia 50 days after the inoculation of Suillus luteus (i.e. mycorrhizal 50d), seedlings harboring fully developed ectomycorrhizas at the end of the experiment (i.e. mycorrhizal EoE), and non-mycorrhizal seedlings. Survivorship (in percent rescaled in the interval $[0,1])$ is expressed as a function of the time (in days). Symbol + indicates censored seedlings (Crawley, 2013). 
Table 1. Fungal genotypes used in the present work.

\begin{tabular}{|c|c|c|c|c|}
\hline $\begin{array}{l}\text { MUT }^{1} \\
\operatorname{accession~} \mathbf{N} .\end{array}$ & Species & $\begin{array}{l}\text { Isolation } \\
\text { date }\end{array}$ & $\begin{array}{l}\text { Isolation } \\
\text { method/substrate }\end{array}$ & Origin \\
\hline MUT00001193 & $\begin{array}{l}\text { Heterobasidion } \\
\text { irregulare }\end{array}$ & 2005 & Airspora samplings & $\begin{array}{l}\text { Castelfusano, RM, } \\
\text { Italy }\end{array}$ \\
\hline MUT00001151 & H. irregulare & 2005 & Airspora samplings & Sabaudia, LT, Italy \\
\hline MUT00003560 & H. irregulare & 2002 & Stump & $\begin{array}{l}\text { Castelporziano, RM, } \\
\text { Italy }\end{array}$ \\
\hline MUT00005731 & H. annosum & 2013 & Airspora samplings & $\begin{array}{l}\text { artificial } \\
\text { heterokaryotic } \\
\text { genotype }\end{array}$ \\
\hline MUT00001143 & H. annosum & 2007 & Fruiting body & Sabaudia, LT, Italy \\
\hline MUT00001204 & H. annosum & 2005 & Airspora samplings & Sabaudia, LT, Italy \\
\hline MUT00005740 & Suillus luteus & 2009 & Fruiting body & $\begin{array}{l}\text { Lommel Sahara, } \\
\text { Limburg, Belgium }\end{array}$ \\
\hline
\end{tabular}

${ }^{1}$ MUT Mycotheca Universitatis Taurinensis 
Table 2. Log-rank test comparing Kaplan-Meier survival curves. Curves of seedlings displaying mycorrhizal primordia 50 days after the inoculation of Suillus luteus (i.e. mycorrhizal 50d) and seedlings harboring fully developed ectomycorrhizas at the end of the experiment (i.e. mycorrhizal EoE) are compared to curves of non-mycorrhizal seedlings inoculated with either Heterobasidion irregulare or H. annosum. Similarly, curves of non-mycorrhizal seedlings are contrasted between seedlings inoculated with either Heterobasidion species. For each comparison, the following data associated with the log-rank test are reported: the total number of seedlings $(\mathrm{N})$, the number of observed dead seedlings $(\mathrm{O})$, the number of censored seedlings $(\mathrm{C})$, the expected number of dead seedlings (E), the $\chi^{2}$ value with its related degrees of freedom (d.f.) and the $P$-value. The symbol * associated with a $\chi^{2}$ value indicates a significant difference between the corresponding Kaplan-Meier survival curves $(P$-value $<0.05)$.

\begin{tabular}{|c|c|c|c|c|c|c|c|c|}
\hline Species & $\begin{array}{l}\text { Seedlings } \\
\text { mycorrhization status }\end{array}$ & $\mathbf{N}$ & $\mathbf{O}$ & $\mathbf{C}$ & $\mathbf{E}$ & $\begin{array}{l}\text { log-rank } \\
\text { test } \chi^{2}\end{array}$ & d.f. & $P$-value \\
\hline \multirow[t]{2}{*}{ H. irregulare } & mycorrhizal 50d & 21 & 20 & 1 & 24.2 & 2.68 & 1 & $1.010 \cdot 10^{-1}$ \\
\hline & non-mycorrhizal & 21 & 20 & 1 & 15.8 & & & \\
\hline \multirow[t]{2}{*}{ H. irregulare } & mycorrhizal EoE & 10 & 9 & 1 & 11.6 & 1.30 & 1 & $2.540 \cdot 10^{-1}$ \\
\hline & non-mycorrhizal & 21 & 20 & 1 & 17.4 & & & \\
\hline \multirow[t]{2}{*}{ H. annosum } & mycorrhizal 50d & 21 & 18 & 3 & 25.9 & $11.70 *$ & 1 & $6.320 \cdot 10^{-4}$ \\
\hline & non-mycorrhizal & 21 & 21 & 0 & 13.1 & & & \\
\hline \multirow[t]{2}{*}{ H. annosum } & mycorrhizal EoE & 9 & 9 & 0 & 14.2 & $7.28^{*}$ & 1 & $6.970 \cdot 10^{-3}$ \\
\hline & non-mycorrhizal & 21 & 21 & 0 & 15.8 & & & \\
\hline H. irregulare & non-mycorrhizal & 21 & 20 & 1 & 19.0 & 0.13 & 1 & $7.110 \cdot 10^{-1}$ \\
\hline
\end{tabular}


H. annosum non-mycorrhizal

$\begin{array}{llll}21 & 21 & 0 & 22.0\end{array}$ 
Table 3. Spearman's correlation analyses between the time to death and the mycorrhizal density of all seedlings inoculated with Heterobasidion spp. and of the two subsets of seedling inoculated with either H. irregulare or H. annosum. For all correlations, the table shows: the Spearman's $\rho$ coefficient, the number of seedlings $(\mathrm{N})$, the associated value of the S statistics along with the corresponding $P$-values calculated from the exact $\left(P_{e}\right)$, AS $89\left(P_{A S 89}\right)$ and $\mathrm{t}\left(P_{t}\right)$ distributions. The symbol * indicates significant correlations $(P$-values $<0.05)$.

\begin{tabular}{lllll}
\hline Species & $\boldsymbol{\rho}$ & $\mathbf{N}$ & $\mathbf{S}$ & $\boldsymbol{P}$-values \\
\hline & & & & $P_{e}=2.465 \cdot 10^{-2}$ \\
Heterobasidion spp. & $0.253^{*}$ & 79 & 61362.00 & $P_{A S 89}=2.465 \cdot 10^{-2}$ \\
& & & & $P_{t}=2.439 \cdot 10^{-2}$ \\
& & & & $P_{e}=4.932 \cdot 10^{-1}$ \\
H. irregulare & 0.111 & 40 & 9474.70 & $P_{A S 89}=4.932 \cdot 10^{-1}$ \\
& & & & $P_{t}=4.946 \cdot 10^{-1}$ \\
H. annosum & & & & $P_{e}=7.377 \cdot 10^{-3}$ \\
& $0.425^{*}$ & 39 & 5677.00 & $P_{A S 89}=7.377 \cdot 10^{-3}$ \\
& & & & $P_{t}=6.939 \cdot 10^{-3}$ \\
\hline
\end{tabular}

